\title{
Article
}

\section{Ethics in corporate research and development: can responsible research and innovation approaches aid sustainability?}

Stahl, Bernd, Chatfield, Kate, Ten Holter, Carolyn and Brem, Alexander

Available at http://clok.uclan.ac.uk/29518/

Stahl, Bernd, Chatfield, Kate ORCID: 0000-0001-8109-0535, Ten Holter, Carolyn and Brem, Alexander (2019) Ethics in corporate research and development: can responsible research and innovation approaches aid sustainability? Journal of Cleaner Production, 239 (118044). ISSN 0959-6526

It is advisable to refer to the publisher's version if you intend to cite from the work. http://dx.doi.org/10.1016/j.jclepro.2019.118044

For more information about UCLan's research in this area go to http://www.uclan.ac.uk/researchgroups/ and search for <name of research Group>.

For information about Research generally at UCLan please go to http://www.uclan.ac.uk/research/

All outputs in CLoK are protected by Intellectual Property Rights law, including Copyright law. Copyright, IPR and Moral Rights for the works on this site are retained by the individual authors and/or other copyright owners. Terms and conditions for use of this material are defined in the policies page. 


\section{Journal Pre-proof}

Ethics in corporate research and development: can responsible research and innovation approaches aid sustainability?

Bernd Carsten Stahl, Kate Chatfield, Carolyn Ten Holter, Alexander Brem

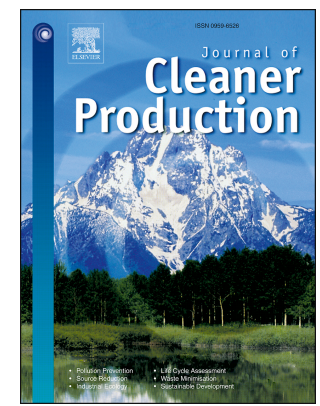

PII:

S0959-6526(19)32914-2

DOI:

https://doi.org/10.1016/j.jclepro.2019.118044

Reference: JCLP 118044

To appear in: Journal of Cleaner Production

Received Date: 22 December 2018

Revised Date: 12 August 2019

Accepted Date: 13 August 2019

Please cite this article as: Stahl BC, Chatfield K, Holter CT, Brem A, Ethics in corporate research and development: can responsible research and innovation approaches aid sustainability?, Journal of Cleaner Production (2019), doi: https://doi.org/10.1016/j.jclepro.2019.118044.

This is a PDF file of an article that has undergone enhancements after acceptance, such as the addition of a cover page and metadata, and formatting for readability, but it is not yet the definitive version of record. This version will undergo additional copyediting, typesetting and review before it is published in its final form, but we are providing this version to give early visibility of the article. Please note that, during the production process, errors may be discovered which could affect the content, and all legal disclaimers that apply to the journal pertain.

(C) 2019 Published by Elsevier Ltd. 


\section{Ethics in corporate research and development: can Responsible Research and Innovation approaches aid sustainability?}

\section{Bernd Carsten Stahl}

Affiliation: Centre for Computing and Social Responsibility, De Montfort University

Address: The Gateway, Leicester LE19BH, UK

Telephone: +441162078252

Email: bstahl@dmu.ac.uk

\section{Kate Chatfield}

Affiliation: Centre for Professional Ethics, University of Central Lancashire

Address: Corporation Street, Preston, PR1 2HE.

Telephone: +441772893697

Email: kchatfield@uclan.ac.uk

\section{Carolyn Ten Holter}

Affiliation: Department of Computer Science, University of Oxford

Address: Wolfson Building, Parks Rd, Oxford OX1 3QD

Telephone: +441865283580

Email: carolyn.ten.holter@cs.ox.ac.uk

\section{Alexander Brem*}

Affiliation: Chair of Technology Management, Friedrich-Alexander-Universität Erlangen-

Nürnberg (FAU)

Address: Fürther Str. 246c, 90429 Nürnberg, Germany

Telephone: +499115302966640

Email: alexander.brem@fau.de

* Corresponding author 


\section{Ethics in corporate Research and Development (R\&D): can Responsible Research and Innovation (RRI) approaches aid sustainability?}

\section{ABSTRACT}

An increase in the number of companies that publish corporate social responsibility (CSR) statements, and a rise in their 'sustainability' research, reflects a growing acceptance that broad ethical considerations are key for any type of company. However, little is known about how companies consider moral objectives for their research and development (R\&D) activities, or the basis upon which these activities are chosen. This research involves qualitative investigation into Responsible Research and Innovation (RRI) in the Information and Communication Technology (ICT) industry, comprising 30 in-depth, pan-European interviews with key personnel in the industry, and focus groups with employees at 14 different companies. Through investigation of the 'responsible' activities these companies currently undertake, we shed light on the types of moral goals they set and their underlying ethical standpoints. By reviewing both the responsible innovation and sustainability discourses, and presenting phenomenological evidence, we demonstrate that companies have adopted some aspects of RRI, even though it might not be recognised as such. Our findings indicate that these innovators recognise some of the ethical and societal concerns associated with their activities but their approach is often piecemeal; primary focus is upon the most immediate issues and on legal compliance, to the detriment of broader societal issues and wider challenges. We recommend explicit mechanisms that draw upon established ethical thought and practical academic work to improve companies' abilities to carry out their sustainability activities, and incorporate them into a responsible business strategy. We conclude with recommendations for innovators, corporate research and development, and policy.

Keywords: research and development; sustainability; Responsible Research and Innovation; ethics; ICT 


\section{INTRODUCTION}

The most recent "State of the Future" (2017) report from the Millennium Project painted a stark picture of the challenges that face humanity in the $21^{\text {st }}$ century including radical climate change, increasing energy demands, population growth, and lack of access to clean water etc. It is against this background that the EU supports and promotes the practice of Responsible Research and Innovation (RRI) which entered mainstream academic debate as a form of research governance less than a decade ago (von Schomberg, 2013).

With a solid tradition of reflection on the consequences of research and novel technologies, the RRI discourse highlights the importance of anticipating future outcomes and dealing with uncertainty (Adam and Groves, 2011). The theme of uncertain futures is persistent in frequently stated goals of RRI, which are often linked with addressing grand social challenges (Boden et al., 2012). These are described as 'wicked' problems (Cagnin et al., 2012) that require interdisciplinary collaboration (Winter and Butler, 2011) and novel thinking. Innovation is thus viewed as a natural way to address them (Murray et al., 2012). Several high-level political bodies have attempted to define these challenges, notably the European Commission (EC) which organises approximately one third of its funded research around such challenges ${ }^{1}$ and the United Nations with its 17 sustainable development goals (SDGs) ${ }^{2}$. The RRI discourse has, to a large extent, adopted these grand challenges as aims that responsible research and innovation should address (Levidow and Neubauer, 2012), thus providing a route-map for research and innovation. In addition to these goals, there is strong emphasis in the RRI discourse about the creation of 'democratic legitimacy through RRI-related processes', notably, public engagement (Anichini and Cheveigné, 2012).

Notwithstanding slight differences in perspectives about the meaning of RRI, there is broad agreement that when researchers adopt the central tenets and ethos of RRI, this can help to ensure that research and innovation contribute in a useful and responsible way to developing solutions that address pressing societal problems (Leisinger and Chatfield, 2019). Furthermore, in-built requirements for the European Commission's funding schemes like the Horizon 2020 programme,

\footnotetext{
${ }^{1}$ Health, demographic change and wellbeing; food security, sustainable agriculture and forestry, marine and maritime and inland water research, and the bioeconomy; secure, clean and efficient energy; smart, green and integrated transport; climate action, environment, resource efficiency and raw materials; Europe in a changing world - inclusive, innovative and reflective societies; secure societies - protecting freedom and security of Europe and its citizens. (https://ec.europa.eu/programmes/horizon2020/en/h2020-section/societalchallenges)

${ }^{2}$ http://www.un.org/sustainabledevelopment/sustainable-development-goals/
} 
ensure that many publicly-funded researchers engage actively with RRI. However, there is a lack of understanding about whether and how this is reflected in the private sector (Martinuzzi et al., 2018). Historically, private companies have not concerned themselves directly with grand social challenges. However, the rise of corporate social responsibility movements in the latter part of the $20^{\text {th }}$ century could be interpreted as acknowledgement that private companies do in fact have an important role to play in addressing societal concerns. A search on Google Scholar for the phrase 'corporate social responsibility' shows a strong upward trend, with over 61,000 results since 2016 . The same pattern in more socially-conscious and 'future-aware' attitudes, is reflected in a search in the Journal of Cleaner Production for the term 'sustainability'. This reveals increasing numbers of articles each year since 1995, with 2,703 articles so far in 2019 (as at 30-07-2019). In private companies, evidence of rising concern about their impacts on both society and the environment, suggests that a framing of the 'private sector' as somehow set apart from the 'public' life of society is an outdated model. Furthermore, relatively new concepts such as 'green human resource management' also point to rising concerns in industry about corporate impacts on the environment (Chiappetta Jabbour et al., 2019; Yong et al., 2019). Indeed, private companies are integral to the fabric of society and, as such, they share in the responsibility for addressing societal challenges. Additionally, given the importance of the reciprocal relationships between private businesses and academic research in the development of technologies, this is a significant lacuna in the research literature.

The overarching aim of this research is to investigate how, why and to what extent private information and communication technology (ICT) companies engage with ethical and societal challenges. Through the framework of RRI, we examine the relationship between (moral) objectives, (ethical) justification and RRI, and how these can link to corporate sustainability initiatives. Three research questions frame the empirical investigation:

1. What are the current RRI related activities?

2. How are the current activities implemented?

3. Why are these activities undertaken?

Through findings from question 1, we are able to infer the responsibility horizons for these ICT companies. Through questions 2 and 3, we are able to infer the moral aims for their innovations, the ethical justification for these aims and how they are addressed.

In the following section we outline the background to this research. In an overview of relevant literature, we discuss the ethical underpinnings of organisational decisions, touching on the RRI discourse, the sustainability discourse, and examine how these might be related. We then discuss 
how ethical issues are embedded within the technical field of Information and Communication Technology (ICT) innovation.

\section{BACKGROUND}

RRI has broad interdisciplinary underpinnings including the notion of 'responsible development' as, for example, in the US 2003 21st Century Nanotechnology Research and Development Act (US Government Printing Office, 2003). It draws upon and extends a number of established positions and traditions, including innovation studies, science and technology studies, philosophy of technology and technology assessment (Landeweerd et al., 2015). One of the most widely used definitions of RRI (von Schomberg, 2013) focuses on both the processes and products of research and innovation with the normative anchor points of ethical acceptability, sustainability and social desirability as key facets for assessment of inherent RRI value. Broadly similar approaches can be seen in industry but these are often framed in alternative language such as 'sustainable innovation' (Berkowitz, 2018).

While discussion and debate about the precise nature of RRI is ongoing (Chatfield et al., 2017), there are recurrent themes that emerge from the discourse. The most enduring of these include:

i) the requirement for research and innovation to align with societal needs,

ii) the necessity of anticipating and being responsive to ethical, environmental and societal concerns, and

iii) the need to enhance these efforts through engagement with a broad range of stakeholders (Owen et al., 2013).

Building on this broad consensual basis, the European Commission (2014) explains how the concept of RRI incorporates a number of pillars, each corresponding to an established research policy area. These are:

- Public engagement: Incorporating the views, opinions and concerns of stakeholders in the research process to ensure that research and innovation are aligned with societal interests.

- Open access: Including the use of online technologies to make academic research more accessible and (preferably) free to read, as well as concepts such as open data and open science more generally.

- Gender equality: A one-sided representation of gender in research and innovation can lead to poor outcomes in terms of both scientific quality and societal relevance.

- Ethics: Compliance with, and governance by, ethical codes forms an integral part of academic research. 
- Science education: Public education in science increases both understanding of, and engagement with, research and innovation.

These pillars constitute the essential components of the 'science with and for society' (SwafS) objective for ongoing European Commission funded projects but while they identify key substantive aspects that RRI should cover, there has been a parallel discourse related to RRI processes. These discussions, often taking their point of reference from Stilgoe et al. (2013), focus on the anticipation of possible consequences, reflection within the research process, engagement with stakeholders and responsiveness to external intervention. This view of RRI has been central to much of the academic dialogue and has shaped research policy in certain fields, for instance, the UK Engineering and Physical Sciences Research Council (Owen, 2014).

The literature provides relatively few examples of what RRI is intended to achieve on a practical level; it commonly takes for granted the idea that research and innovation are fundamentally positive and that RRI can help to achieve benefits while averting the downsides (UK Synthetic Biology Roadmap Coordination Group, 2012). However, incentives (like grant funding) for the adoption and application of RRI in the public sector may simply not be present in the private sector. Hence, if RRI is to become more broadly espoused, it is important to understand the objectives and justifications of RRI. This raises the question of why an organisation should wish to pursue RRIrelated goals. In academia, the question is rarely posed because the perception of grand challenges as being in need of solution is highly compelling. Such quests are intuitively plausible; who would argue against the eradication of hunger or the reduction of inequality? Furthermore, they are intrinsically linked to well-established frames of reference, notably human rights (Ruggie, 2010), international agreements such as the UNESCO code, the UN global compact (Leisinger, 2007) and national or regional agreements and legislation like the treaties of the European Union (Schomberg, 2012). Similarly, it is hardly necessary to argue in favour of sustainable innovation (Boons et al., 2013) and RRI incorporates important aspects of sustainability (Martinuzzi et al., 2018).

\subsection{ETHICAL UNDERPINNINGS}

In order to understand the development and the practice of RRI, it is helpful to draw a distinction between the substantive goals that RRI is meant to achieve and the justification of these goals. This distinction mirrors one that can be found in philosophical ethics between morality, as the observable fact of broadly shared views of right and wrong, and ethics, as the reflection of these moral norms. This distinction is more commonplace in continental European philosophy but it also finds its place in Anglo-American applied ethics: 
Ethics studies morality. Morality is a term used to cover those practices and activities that are considered importantly right and wrong; the rules that govern those activities; and the values that are embedded, fostered, or pursued by those activities and practices (De George, 1999, p. 19).

By drawing upon this distinction, one can differentiate between what RRI is supposed to achieve (morality) and why this is deemed to be worthy of achievement (ethics). This is helpful because it allows identification of both what companies aim to achieve by being responsible and why they think achieving this is desirable.

The question of the ethical justification of these goals is highly relevant. Any individual may support a particular moral goal but that does not mean that they are moved to pursue it actively. To some degree, one can argue that the survival and long-term viability of the organisation has an important moral quality but here we focus on the ethical influences that provide a basis for moral obligations.

The field of ethics is complex and multi-dimensional, but the most relevant concepts to include here are applied and normative ethics.

Applied ethics concerns the moral permissibility of specific actions, and discussion about particular ethical challenges in science and research governance takes place largely at this level. Most prominent among the principles of applied ethics are the themes of autonomy, beneficence, nonmaleficence and justice. While these four principles provide an established foundation for biomedical ethics (Beauchamp and Childress, 2009), they are now widely applied in all areas of research and innovation, beyond their origins in biomedical research (Bailey et al., 2011).

However, in our investigation, we look beyond this functional approach to investigate companies' ethical underpinnings at a normative level, seeking to uncover underlying assumptions about what is 'right' and what is 'legitimate', that inform practice. Normative ethics is concerned with the standards and principles used to determine whether something is right or good and is itself commonly divided into various sub-branches. Ethical arguments for the support of responsible activity often refer directly to normative ethical theories (Pandza and Ellwood, 2013) and the normative stance most commonly taken when appraising science and research is utilitarian (Mill, 1861). This is the viewpoint that the ethical value of an action is determined by the benefit (utility) of its consequences and, simply speaking, a utilitarian will weigh up the potential harms and benefits of an action when deciding upon the 'right' course of action. This pragmatic approach would be familiar to anyone running a company. However, hypothetically, utilitarianism could also be used to justify any means to achieve desirable ends and most people would accept that they have duties or 
obligations that are distinct from the outcomes. For example, most would not condone the killing of a healthy human in order to save the lives of many others in need of organ transplants. This is the position of deontology, most notably linked to the philosopher, Immanuel Kant $(1797,1788)$, which is concerned with the duties and obligations. A third classical position, with clear bearings on research and innovation, is that of virtue ethics, which finds its roots in classical Greek philosophy, particularly, Aristotle (Nicomachean Ethics, republished 2007). Virtues refer to characteristics of the person, rather than the qualities of their actions, and ethical value is enhanced when individual moral character is developed. These normative underpinnings are important because they motivate actors to engage in responsible activities such as RRI, and they may also indicate which actions are more likely to be pursued.

We are by no means asserting that there is a simple way to untangle the underpinnings of corporate ethical standpoints. However, we do believe it is possible to identify trends in practice that can provide clues about normative influences as we demonstrate through our empirical work. Our studies focus upon private ICT innovators and this sphere of corporate innovation faces a multitude of societal and ethical challenges, many of which are newly emerging, as outlined in the following section.

\subsection{ICT, ETHICS AND INNOVATION}

The fact that ICT can raise ethical questions has been acknowledged since its initial development (Wiener, 1954) and the impacts on users, and on the viability of businesses that fail to take these concerns seriously, can be immediate and significant. These questions cover a broad spectrum of ethical issues and are of a very diverse nature. For example, there are well-defined concerns, such as privacy and data protection; more socially pressing concerns, such as unemployment caused by autonomous machines; and conceptually challenging concerns, such as the possibility of moral agency for machines.

Ever-increasing capabilities through automation have long been associated with the question of appropriate use of ICT (Dreyfus, 1992). More recently, there has been intensive debate about many aspects of ICT, from the likely ethical and social consequences of big data (Gransche, 2016), robotics (Borenstein, 2012; Richardson, 2017, 2016) and artificial intelligence (Cath et al., 2016), to how millennials deal with data security (Fodor and Brem, 2015). These issues are of such national and international concern that policymakers have launched a number of initiatives to better describe and understand the consequences of these developments and develop policy responses. These include the UK Parliament (Big Innovation Centre, 2017); work from the European Parliament, (2017); the 
Executive Office of the President, (2016a, 2016b) and the House of Commons Science and Technology Committee, (2016). High-level ethical guidance and principles are in abundance (Winfield, 2019).

The availability of personal networked computing, in conjunction with the general spread of the internet and the World Wide Web, has facilitated the now ubiquitous use of e-commerce and social media; both e-commerce and social media have contributed greatly to the boom of academic reflection on ethics and computing. A review of the computing-related literature (Stahl et al., 2016) analysed a large body of work focusing on the questions of ethics in ICT in the context of innovation. While the most prominent topic in this discourse concerns privacy and data protection, there are numerous other topics such as professional duties, work-related issues, autonomy, agency, trust, consent, identity, security, harm, justice and online piracy. Innovators are generally good at addressing ethical issues at early stages in research and development, and recognise that responsibilities are interrelated (Timmermans et al., 2017), but the broad-based and longer-term impacts of ICT innovations can be difficult to imagine, let alone assess. Discussion of the associated ethical issues has increased with the spread of new technologies and has been further accelerated through the mass adoption of social media (Fuchs, 2017). Social media can provide end users with a platform for sharing their experiences and opinions and this has resulted in many high-profile cases, which further raises awareness. It demonstrates that ethical questions can be intrinsic to ICT and one might assume that companies developing these technologies ought to be aware of these highprofile debates.

\subsection{RRI AND SUSTAINABILITY}

Sustainability has been defined as "meeting the needs of a firm's direct and indirect stakeholders ... without compromising its ability to meet the needs of future stakeholders as well" (Dyllick and Hockerts, 2002, p131). The key here being the concept of continuity (Brundtland, 1987); sustainability enables the operations of an enterprise to be, hypothetically, infinite. This requires deep regard for the context, both local and global, within which the business is situated. It necessitates a much broader view than simple profitability and has led to initiatives such as the World Business Council for Sustainable Development, whose 200 members oversee numerous projects that examine governance, human rights, energy and many other issues that tie together to produce a framework within which to consider the meaning of true sustainability (WBCSD, n.d.). The thrust of Dyllick \& Hockerts' argument is that economic sustainability is inadequate as a goal without consideration of social and environmental sustainability. Without this 'triple bottom line', business 
cannot hope to survive in the longer term. There are obvious alignments here with the aforementioned political work, such as the UN's Sustainable Development Goals.

The parallels with the findings from academic investigation of RRI are also clear. While economic sustainability is not a direct goal of RRI, the ethical underpinnings of responsible innovation frameworks that aim to anchor research and development within broader societal structures, can provide businesses with a route map for the societal and environmental sustainability questions they need to consider to achieve true business sustainability (Leisinger and Chatfield, 2018). What is not well known, however, is how companies engage with these questions, what ethical positions and arguments they use and how this translates (or not) into corporate practice. These were undertakings for our empirical work, which we now describe.

\section{Methodology}

\subsection{METHODOLOGICAL APPROACH}

An interpretive perspective to investigation was adopted in this research with the intention of understanding the matters in question through the meanings the selected participants assigned to them (Orlikowski and Baroudi, 1991). The interpretivist approach is essentially concerned with meaning and the quest to understand shared definitions (Schwandt, 2014), of trying to make sense of the world from the subjective experiences of individuals. Since interpretive researchers strive for better understanding of the world through human experience, they employ meaning-oriented methods, such as interviews, focus group discussions and naturalistic observation data collection methods (Antwi and Hamza, 2015). Via these sorts of qualitative methods, the interpretivist perspective is suitable for generating rich descriptions and depth of understanding. Thorne (2016) describes this approach as providing a 'bridge' between objective neutrality and abject theorizing. It can produce results that are academically credible as well as practical, and there is nothing unusual about this approach in either academia or the business world. In business research, qualitative methods are becoming increasingly important. As Eriksson suggests, these methods open the possibility of adopting a critical and reflexive view about the social world of business and its core processes (Eriksson and Kovalainen, 2015).

While qualitative researchers have the choice of different forms of data collection, we selected a combination of in-depth interviews and focus groups as the most appropriate for addressing our research questions. Interviews allow researchers to explore participants' attitudes, beliefs and concepts at a deeper lever than most other methods (Opie, 2004). Furthermore, the use of 
interviews is also recognised as being highly appropriate for investigation of topics where the data might not be available in other forms, where it might only be found amongst key informants or people who are "key players in the field" (Denscombe, 2014).

Focus groups are often integrated into multi-methods design; they can add an extra dimension to the sort of information that is gathered via in-depth interviews. As well as providing a direct route to individual experiences and opinions, they also allow for analysis of the interactional context in which the data is collected (Barbour, 2018). While the interviews were conducted with industry personnel who held key roles in their companies, the focus groups consisted of people with a wider range of roles, including project workers, developers and so on.

\subsection{Data COLlection}

Two sources of data were used for this research:

- Qualitative data from 30 in-depth interviews with key ICT industry personnel.

- Qualitative data from focus groups that included representatives from 14 different ICT companies.

Purposeful sampling was implemented in both of the data collection activities, to ensure that participants had the relevant experience, and were able to provide a variety of perspectives from different countries and different-sized corporations. A range of ICT companies/contacts were identified through existing networks and contacts across Europe. From these, a select number were invited to participate in each activity with the aim of including a cross-section of roles, locations, sizes and types of ICT company. The identified companies were all innovators of ICT services and products for healthy aging and wellbeing.

\subsubsection{Interviews}

The primary aim of the qualitative interviews was to capture the experience and opinions of ICT thought-leaders on the concept and potential value of RRI in the ICT sector. Through in-depth exploration with key players, we sought insider perspectives on the applicability, relevance and values of RRI for the ICT industry, highlighting potential challenges, drivers, and practical implications for their companies and society.

30 in-depth interviews were conducted by nine interviewers in eleven different countries across Europe. Each interview lasted approximately 45-60 minutes. They were conducted either in person, via Skype or telephone. The use of native speakers in each language helped to ensure that language was not a barrier to participants' ability to express themselves with clarity and nuance. To ensure 
consistency between the interviews, a semi-structured interview framework was used to guide the topics of investigation. The interview outline is attached at Appendix A. The interviews were audio recorded, transcribed, translated into English where necessary and anonymised before being passed securely to a central team of two researchers for analysis.

\subsubsection{Focus groups}

The goal of the focus groups was to gain deeper insights into the real-world applicability of RRI implementation within different types of companies in the ICT sector. Each of these companies was engaged in the development of new technologies, whether products or services, for health and wellbeing. In total, representatives from fourteen technology companies engaged in focus groups across seven EU countries. Each focus group was held in person, facilitated by the same researchers who conducted the interviews and who were located in the country. Each lasted approximately $180-$ 240 minutes. As with the interviews, the focus groups followed a semi-structured schedule. The framework for the focus groups is attached at Appendix B. The sessions were audio-recorded, transcribed, translated and anonymised before being passed securely for analysis by the central team of two. Table 1 gives an overview of the data sources.

\begin{tabular}{|l|l|l|l|l|}
\hline Study activity & $\begin{array}{l}\text { Number of } \\
\text { participants }\end{array}$ & Locations & $\begin{array}{l}\text { Company } \\
\text { sizes }\end{array}$ & Description \\
\hline $\begin{array}{l}\text { In-depth } \\
\text { Interviews } \\
\text { with key } \\
\text { players in }\end{array}$ & $\begin{array}{l}30 \\
\text { individuals }\end{array}$ & $\begin{array}{l}\text { Cyprus, Denmark, } \\
\text { Finland, France, } \\
\text { Germany, Italy, } \\
\text { Netherlands, Spain, } \\
\text { Sweden, } \\
\text { Switzerland, UK }\end{array}$ & $\begin{array}{l}19 \text { SMEs } \\
11 \text { large } \\
\text { companies }\end{array}$ & $\begin{array}{l}\text { Qualitative, in-depth interviews } \\
\text { using a semi-structured interview } \\
\text { schedule. Conducted 2015-2016. }\end{array}$ \\
\hline Focus groups & 14 groups & $\begin{array}{l}\text { Cyprus, Denmark, } \\
\text { Finland, Germany, } \\
\text { Italy, Netherlands, } \\
\text { UK }\end{array}$ & $\begin{array}{l}10 \text { SMEs } \\
\text { 4 large } \\
\text { companies }\end{array}$ & $\begin{array}{l}\text { Focus groups with company } \\
\text { representatives, facilitated via a } \\
\text { semi-structured discussion } \\
\text { schedule. Conducted 2016-2017. }\end{array}$ \\
\hline
\end{tabular}

Table 1: Overview of data sources

\subsection{ETHICS}

The data collection activities were conducted in accordance with ethical principles such as informed consent, respect for privacy, and avoidance of harm and deception and were approved by Leicester DeMontfort University Faculty Research Ethics Committee and the STEMH Research Ethics Committee at the University of Central Lancashire. 


\subsection{DATA ANALYSIS}

For both the focus group and interview qualitative data, the same method of thematic analysis was utilised. Given that we had a specific goal in mind for our analysis (to identify the current practices that relate to RRI, as well as any specified aims and justifications), we employed a form of theoretical thematic analysis through application of an analysis template. In contrast to the largely inductive approach to analysis that is frequently utilised to identify and explore emergent themes and theories in qualitative data, we acknowledge that our approach to analysis is more explicitly analyst-driven. Such a theoretical approach to analysis does not provide a rich description of the data overall; it is a selective approach that can provide detailed analysis of certain aspects of the data and is particularly relevant when researchers are attempting to answer a specified research question (Braun and Clarke, 2006). Furthermore, this approach works well when there is a desire to examine specific topics within a large data set (Brooks et al., 2015). More specifically, we utilised template analysis along the lines described by King (2012), who emphasises the adaptable nature of this approach. Template analysis is a technique rather than a methodological stance that can be used from a variety of philosophical perspectives. This technique allows the researcher to develop themes from the data that are most relevant to the research question and this can include both descriptive and interpretive themes. Consequently, this method provides a relatively high degree of structure to the analysis (through the template) without restricting the researcher to face-value descriptions of the data. For template analysis to be effective in addressing a specified topic, it is vital that the structure of the template is aligned with the aims or research question.

In our case, there are three research questions and our assumption is that analysis of the what, how and why of RRI-related activities can help understanding of which processes companies currently use to identify and address challenges. These three aspects (what, how and why) therefore, frame the analysis and form the basis of simple analysis template as shown in Table 2. Each question/theme may be represented within the data by a number of components as detailed in the descriptions. 


\begin{tabular}{|c|c|c|c|}
\hline Question & Description & \multicolumn{2}{|l|}{ Shows us } \\
\hline $\begin{array}{l}\text { What are the } \\
\text { current RRI related } \\
\text { activities? }\end{array}$ & $\begin{array}{l}\text { To include elements of RRI as detailed } \\
\text { by the EU (public engagement, open } \\
\text { access, gender, ethics, science } \\
\text { education) as well as any other } \\
\text { activities are believed to be relevant }\end{array}$ & & $\begin{array}{l}\text { The responsibility } \\
\text { horizon for the } \\
\text { companies }\end{array}$ \\
\hline $\begin{array}{l}\text { How are the } \\
\text { current activities } \\
\text { implemented }\end{array}$ & $\begin{array}{l}\text { To include the set processes, } \\
\text { procedures and policies that are in } \\
\text { place (or absent) as well as actual } \\
\text { practice. }\end{array}$ & \multirow[t]{2}{*}{$\longrightarrow$} & \multirow{2}{*}{$\begin{array}{l}\text { The moral aims for } \\
\text { their innovation; } \\
\text { the ethical } \\
\text { justification for } \\
\text { these aims and } \\
\text { how they are } \\
\text { addressed. }\end{array}$} \\
\hline $\begin{array}{l}\text { Why are these } \\
\text { activities } \\
\text { undertaken }\end{array}$ & $\begin{array}{l}\text { To include motivations behind the what } \\
\text { and the how. }\end{array}$ & & \\
\hline
\end{tabular}

Table 2: Data analysis template and themes

The data analysis was undertaken by two researchers and in three stages. For the first stage, the researchers worked independently to read the transcriptions from the two data sources and identify all information that was relevant to the analysis template. In stage two, they came together to sort the two data sets with the aid of NVivo qualitative software, extracting all relevant information and coding it via application of the template. In stage three, the coded data for each a priori theme was subjected to a further round of thematic analysis. For this analysis, the two researchers worked together, discussing until they reached a consensus upon trends, disparities and gaps. These findings are presented in the following section.

\section{FindingS}

The results of the research have been divided into sections corresponding to the research questions, the what, how and why of dealing with ethical issues. As the project that informed the paper was a European-funded one, our investigation of the RRI activities being undertaken within industry is informed by the European Commission's structure of the five RRI pillars discussed earlier (European Commission, 2012). However, it also goes beyond these pillars where activity that was directed towards a 'responsible' approach did not easily correspond with the framework.

The results from the two separate qualitative methods have been pooled here because there were not significant differences between the two sets. Where quotations are used to illustrate the main points, these are referenced by interview (I) number or focus group (FG) number. 


\subsection{WHAT ARE THE CURRENT RRI-RELATED ACTIVITIES?}

When asked in what ways they discharge their responsibilities, our respondents referred, whether explicitly or tacitly, to most of the 'pillars' discussed in the European RRI literature, albeit to very different degrees.

\subsubsection{Public engagement}

There was general agreement on the value of public engagement. However, public engagement is seen very much in terms of outreach to end users and not necessarily as the type of stakeholder involvement directed towards co-creation from the outset, which is the focus of the RRI public engagement pillar.

"The most significant action in our development work is to involve the end-users into process. All research and development should be based on actual needs and have significant meaning to the target group." (FG.5)

\subsubsection{Open access}

The topic of sharing of data or outcomes was complex and sensitive for the participants. Open access is not widely practised in the private sector for obvious reasons, but some companies do share data to a limited extent. Participants were aware of the tensions in this area between intellectual property and open access. Despite an appreciation of the potential benefits, various obstacles to sharing more broadly were named, which could be summarised as fear of damage to the company's bottom line.

\subsubsection{Ethics}

The question of ethics was much more prominent in our respondents' thinking. Internally developed protocols and standards for responsible-type activity were identified by more than half of the participants but these varied widely, from seeking ethical approval for research activity, to having separate units for ensuring corporate social responsibility. A few have well-developed procedures:

"In my company activities are carried out with great attention to the social and environmental impact, as for example trying to use recyclable materials and to save energy." (I.5)

In respect of external tools, some described the use of tools and standards but also highlighted the complexity of this given the differing requirements for trade in different regions and countries. Eight participants stated that they had no internal policy, or use of tools, to guide them. Some, particularly from smaller companies, highlighted that the costs involved, and the time required, can act as a barrier to adoption. 
The focus groups highlighted that ethical review (by committees and panels) is utilised by many and agreed as necessary for various research activities where there may be a potential for harm or where there is ethical uncertainty or unpredictability. However, there is some resistance to ethical review panels as described in the next section.

One interesting point that emerged from the data was that some respondents associated acting responsibly with risk assessment and risk management. When asked about measures that are in place for the prediction of broad impact or long-term consequences of research and innovation, the broad spectrum of responses revealed highly polarized practice. Eight participants stated that there was no consideration at all, such as the following:

"We don't evaluate it." (I. 26)

Conversely, for others, the exact opposite is the case:

"There is ... specific training of personnel on issues of concern for the environment and correct ethical behaviour. Moreover, we support projects with social impact and some starts-up." (I.19)

Several participants described how RRI values were or should be closely aligned with the company ethos. Some of these companies have fairly well-developed systems for addressing RRI-related concerns and they were clear about the potential benefits of RRI. Only a minority of the companies, however, (six of them and all large) had well-developed policies and procedures for the prediction of long-term consequences, such as green policies and long-term risk assessment procedures. There is a clear correlation between size of company and presence of this CSR ethos, tying in with the earlier observation that creation of CSR policy and action was seen as an unacceptable cost for small businesses.

\subsubsection{Science education}

As with gender equality, science education (which the EU sees as one of the pillars of RRI) was not of strong interest to the companies. They saw it as an important activity in society but beyond their responsibility.

\subsubsection{Gender equality}

The EU gender equality pillar did not feature highly in discussions. It was generally seen as important but, in some countries, also already legally regulated. There was little understanding that in areas where gender inequality is starkly an issue, such as STEM industries, companies might have obligations that went beyond strict adherence to regulation. This is reflected in recent work around 
gender pay gaps, where companies may understand that they are obliged to pay men and women the same amount for the same work, but do not accept that they may have a role in creating more equality in terms of the numbers of men and women doing particular types of work (e.g. Boll and Lagemann, (2019) who follow up their findings with a call for more action at the company level).

\subsection{HOW ARE THE RRI-RELATED ACTIVITIES IMPLEMENTED?}

The question of how the activities were implemented depended, to a large degree, on the type of activity in question.

\subsubsection{Public engagement}

This tends to happen in many ways, for example, visiting people, bringing them in, mail, phone, video etc., and takes many forms, like interviews, questionnaires and focus groups. In particular, the use of social media to reach end-users is changing the scale and pace of engagement. Engagement is used for discussion of a range of topics including: performance of the product, quality of the product, acceptance by users, broader acceptance by society, data protection and confidentiality. While end user engagement is broadly appreciated as a tool, there were some concerns about the ability of non-specialists to imagine the capabilities of novel technologies.

\subsubsection{Ethics}

There was a wide disparity in the implementation of ethics-based considerations. These include various types of evaluation and audit:

"We do not apply any standard risk assessment instrument even if risk evaluation is essential part of planning and conducting RDI work. The risks of every project are followed and documented on regular basis and necessary actions/measures are taken." (1.25)

Other organisations use more established methodologies for risk analysis and management but retained the flexibility to respond to issues as they arose:

"Inside the regulatory ISO framework, adopted by our company, we are asked to take into account the risks connected to the deployment of our services/systems. We address these issues with cause/effect methods in the course of ad-hoc meetings." (l.19)

Participants described how, in the absence of specific regulations, internal measures and procedures for risk and ethical analysis need to be developed. However, it is also clear that many are confused about what this would entail and how to go about it: 
"In the social and health care sector, ethical codes of conduct and professional reasoning are closely connected to work practices. However, in technology development this is not so self-explanatory." (FG.14)

Furthermore, there is a sense of inadequate preparation for ethical behaviour:

"I had the feeling that I was not sufficiently trained to deal with this." (I.21)

The lack of understanding about how to behave ethically when not guided by legal regulation or standards-based frameworks raises challenges that could potentially be filled through more coherent and widespread comprehension of RRI.

Our impression is that the larger and more organized companies are more likely to be using specific tools and/or aligning with global initiatives and codes. There was general agreement that some form of instruction is necessary, especially for assessment of novel technologies:

"I think that guidelines are good and directives are good because then we have something to relate to. Because if they don't exist, we guess." (1.30)

For those companies that mentioned the value of instilling an ethical culture, their values seem to pervade all activity, right down to the hiring process as this interviewee described:

"When we are hiring people, we don't hire people based on their diploma, or based on their line on their resume.... we are much more interested by the skills that this person could have acquired outside school and outside universities, and we are also very interested by the culture of these people. We want to make sure that their soul is compatible with the soul of (the company)." (1.9)

Furthermore, it appeared that the culture of these companies had been set by founders/ those in charge.

"Well I personally think that you have to go to this culture development, trying to promote a culture that tries to make the world a better place and then everything else follows almost automatically". (I.15)

The remaining pillars of RRI - gender equality, science education and open access - were in general not specifically addressed, but there was a sense in which an 'ethical' stance to the company was seen as sufficient to ensure that it was meeting its obligations to society. 


\subsection{WHY ARE THESE RRI-RELATED ACTIVITIES UNDERTAKEN?}

Having described which activities these organisations engaged in and how they do this, the crucial question is why they engage with these activities at all? From review of the RRI literature, we know that the ambition of RRI is grand and will require sound ethical justification. Our data has been analysed with a view to understanding our respondents' justifications and these include both implicit and explicit ethical commitments.

\subsubsection{Market benefit}

By far the most prominent theme to emerge is that behaving responsibly is seen as necessary for the success and survival of the organisation. RRI-related activities, particularly public engagement, are undertaken primarily to ensure appropriate and relevant performance of the product, quality and acceptance, as opposed to more general responsible motivations. If products and services are not received well then, ultimately, reputation and profit are affected:

"It would be almost stupid to do something without having all the stakeholders involved....... we would probably be out of business if we don't deliver what works or what solves real need." (I. 13)

Responsible action is regarded as absolutely necessary for economic survival:

"I wonder what's really revolutionary and new about this. A company that acts irresponsibly won't be around very long. A basic requirement is to think economically and responsibly in order to continue to exist as a company." (FG.2)

Among the reasons for adopting responsible practices as a means of ensuring the long-term survival of the organisation, we can identify several strands that are reflective of the literature. One of these is being seen to do the right thing as a means of safeguarding the organisation's reputation. One of the most frequently mentioned motivating factors for consideration of RRI was the potential for improved corporate image or profile. This is naturally associated also with increased profits as it may provide a competitive edge as expressed by this interviewee:

"I would not speak about increased market penetration, but rather about limitation of market loss. In fact, if a customer can choose between similar products/services, one of the key drivers for his/her choice could be the evidence of the product/service compliance with environmental and/or societal requirements." (I.19) 


\subsubsection{Risk avoidance}

As well as bringing long-term benefit to the corporate image, attention to RRI could help to avoid long-term harm:

"Plus the fact that they can avoid future problems or legal complications ...this could bring better products mainly, and less problems in the future." (I.2)

A significant challenge for those who claim that there are direct benefits to the company from inclusion of RRI is exactly how we go about quantifying benefit:

"How can I show which benefits an enterprise has if it invests in ethics or if it makes investments in the protection of the environment?" (I.12)

\subsubsection{Governance}

The use of certification was also mentioned as a potential motivating factor and closely related to the idea of a license to operate, or the recognition that companies rely on societal goodwill to retain the freedom to do business. A key component of this license to operate is the need to comply with legislation:

"Of course, regulations are very important, and they have to regulate, to create this sort of level playing field amongst stakeholders, and to safeguard the basic principles of safety, performance and effectiveness and quality." (I.6)

\subsubsection{Ethical justifications}

A most interesting finding, from our perspective, was that there was relatively little ethical justification for general moral aims, as would be suggested by the RRI literature. Approximately one third of the participants described more altruistic motivations for inclusion of RRI. These were primarily concerned with benefits to the end users and society, sustainability, preservation of the environment and generally 'doing good for humanity';

"In the area of elderly care, technology development should not be carried out only for the sake of personal gain (profit). Instead, it should be linked with a deeper motive of doing something good and in this way to fulfil genuine needs of people." (I.25)

This attitude is replicated in the focus groups. There are those who are explicit about their desire to benefit people's lives; they want to do good and help people. This may be related to the focus of their business, which in this case was healthcare. It is possible that in other sectors the approach would be different. 
"I have certain ideas why I'm working in this sector, why I do this instead of selling credit cards" (FG.10)

Three of the participants also highlighted the point that once profits are taken care of then there is more freedom to pursue higher values:

"In situations of wealth, when all the basic personal needs are covered, a firm can do it [apply RRI]." (I.11)

Two of our participants expressly stated that their companies conduct activities that are not absolutely essential for their survival because they see it as 'good practice'. This was not consciously connected to any underlying ethical framework. However, overall there was very little 'big-picture' understanding of the company as an integral component of the fabric of society and of having a part to play in addressing societal concerns; we did not encounter any particular aspirations to contribute towards SDGs or grand challenges whatsoever. In this sense, the commercial world interpretation of responsible innovation departs significantly from the vision of RRI in the academic discourse.

\section{DisCUSSION}

Our findings indicate that these particular innovators are aware of many of the ethical and social issues that they can expect to encounter, and they employ a range of tools and processes that allow them to identify concerns and challenges, and to engage with them proactively. This places their activities firmly within the sustainability sphere but there are limitations.

\subsection{SHORT-TERMISM}

It is clear from the findings that, despite a significant amount of activity around RRI-type themes, or activity directed towards broad sustainability principles, these actions mirror the academic RRI discourse only to a very limited degree. Our respondents expressed an interest predominantly in their immediate environment, notably in the continued success of their organisation in the marketplace, hence their piecemeal approach.

This attitude corresponds with systems of free market economics dating back to Adam Smith, who was convinced that in market relationships only self-interest motivates people towards a general beneficial outcome (Smith, 1776). Smith argued that 'enlightened self-interest' was the most effective way to motivate companies to engage in responsible behaviour. Our research demonstrates that this is still considered an effective tool today (Leisinger, 2007), despite voices 
calling for more ethical approaches that adopt sustainability frameworks to create a broader, more socially-conscious view (Oliveira de Paula and Negrão Cavalcanti, 2000).

The findings also suggest a strong reliance on market mechanisms for dealing with the ethical challenges of innovation. Most of these innovators, as market participants, tended to define their moral objectives and ethical justification in these terms, as adherence to market principles. The assumption seems to be that any socially undesirable consequences of their activities will be dealt with by market forces and, presumably, be punished through lack of commercial success. Companies must ensure that they adhere to the general rules of the market but do not need to worry overly about moral and social concerns beyond this. This position explains the emphasis on legal compliance as well as engagement with end users, both of which offer a means of ensuring the market is understood and treated appropriately; it has the advantage of minimising complexity to allow innovators to focus on their core activities. However, this represents the 'moral minimum' of activity, to engage purely with requirements that are mandated in order to survive (Carroll, 1991). In addition, and unrecognised by the respondents, failing to address these issues before a product ever comes to market can result in significant lost investment if it turns out to be unacceptable. This may be seen in the slowness with which companies respond when problems are identified; there is a reluctance to accept that their investment must be written off.

To some degree, these attitudes are unsurprising, given that these organisations must compete and survive in the global marketplace; participants are fully aware of the need to conform to market expectations. It is also not surprising that the ethical justifications of the moral aims of the organisations in our study, tend to be relatively narrow. There are also commentators who express scepticism for the future of corporate sustainability approaches (de los Reyes and Scholz, 2019). We surmise from this, that their responsibility horizons are rather low and that the more ambitious aims of RRI, as, for example, represented in the vision to address grand societal challenges (Levidow and Neubauer, 2012) do not figure in their internal narratives. We have discussed how RRI can be imagined as a stepping stone or conduit for research and innovation to address these societal challenges. Our data suggests that this is not reflected in the hit-and-miss approaches to ethical and sustainability considerations found in private companies. Innovators need to understand the bigger picture and why they should move beyond the level of enlightened self-interest and begin to address external goals. RRI represents a useful framework to allow them to do this. We suggest that a deeper understanding of the why of ethical behaviour is an important factor, just as important as the what of the ethical behaviour and may be a key factor for RRI proponents to consider. The ethical justifications that our respondents expressed are immediate and direct; they rely on the justification 
and success of markets and legal compliance. We would argue that this approach is problematic in the longer term and does not represent the best strategy for its purported aim, namely long-term organisational survival.

\subsection{ETHICAL UNDERPINNINGS}

In this research we have attempted to tease out some of the whys of the ethical behaviours that were described by participants, to seek some understanding of their normative underpinnings. Participants did not, in general, question the ethical foundations of their work, which confirms the observation of Pandza and Ellwood, $(2013$, p1118) of a "foundational belief that the work of scientists, correctly applied, was a force for good." However, the importance awarded to the notion of an ethical corporate culture, or sustainability themes, could be interpreted as having a normative underpinning that is akin to virtue ethics. Interestingly, this also suggests that, for these companies, their level of ethical consideration runs deeper than a purely applied ethics approach.

Also visible in the data are themes that align broadly with utilitarian and deontological perspectives. While the participants may be unaware, the actions they see as logical or necessary are often in line with one or other of these ethical standpoints. The implicit utilitarian justification of the market mechanism was not questioned, and a weighing of the harms and benefits was a key feature in risk assessment processes. In terms of deontology, there was total agreement upon the need to comply with legal and regulatory requirements (needed for existence) but also a sense of being at a loss when issues arise for which there are no guidelines or codes of conduct. This situation is likely to be familiar to those who work at the cutting edge of research and development.

Our research shows that the moral objectives of innovators are much more immediate than the ones hypothesised by the RRI discourse. Customer satisfaction, organisational reputation and compliance with the law are frequently stated objectives. These are justified by reference to the general (moral) good of market mechanisms which are embedded in a legal framework that upholds the greater good. These include issues that innovators are well aware of, such as data protection or customer wellbeing. For these issues, the current approach to RRI by innovators works reasonably well as it largely falls within established objectives and is easily warranted. Moreover, companies recognise how to address these issues. However, there is a further set of ethical concerns that our respondents did not consider explicitly, despite increasing public discussion. These are questions such as the impact of innovations on employment, human identity or life chances through, for example, algorithmic biases. These issues constitute blind spots; they are still too far removed from direct impact upon the organisation and do not easily map onto the organisational objectives. They 
are also not formally regulated, and therefore, it is not clear how the ethical background assumptions apply to them but adoption of RRI at an early stage might avoid difficult issues after products are already in the marketplace. In such circumstances, an RRI framework could be directly valuable to corporate sustainability initiatives.

What this analysis shows is that the ethical horizons of corporate research and development differ considerably from what is proposed in the RRI literature. Company ethical horizons tend to be narrow and more focused on specific and well-defined issues rather than loftier grand challenges. This is despite over a decade's worth of increasing awareness of corporate social responsibility and the broader views of corporate societal involvement represented by the sustainability discourse; it would appear that such approaches are not yet 'baked in' to the whole organisation.

\section{IMPLICATIONS AND CONCLUSION}

This research demonstrates clearly that there is a lag between academic hopes and ambitions for RRI and the practices of profit-making organisations. Although frameworks for RRI have achieved relatively high levels of consensus and visibility in the academic world, this value is yet to be recognised in the private sector.

The insights provided by this research are important for several audiences. Companies are explicitly interested in RRI-type activity and undertake a number of actions that can be seen as expressions of RRI. However, they focus on aspects, notably those that are legally mandated or clearly related to immediate returns for their activities. There is a limited longer-term perspective and very little explicit ethical reflection. We argue that organisations would be well-advised to move beyond their current horizons and engage in broader ethical and societal discourse. This has implications not only for companies, but also for other stakeholders involved in the research and innovation ecosystem.

\subsection{IMPLICATIONS FOR THEORY AND PRACTICE IN CORPORATE SUSTAINABILITY}

Even though our innovators appeared to have a clearly defined view of the immediate ethical issues they are likely to encounter, their engagement with broader social and moral issues appears limited. We suggest that this approach is insufficient. Current and emerging ICTs, ranging from office productivity tools and social media, to bio-inspired computing paradigms and quantum technologies, are affecting our individual and collective lives in a significant way. It is no longer possible to regard them as value-neutral tools to achieve some externally defined end if, indeed, they were ever valueneutral (Nuffield Council on Bioethics, 2013). These technologies affect our lives as workers, citizens, 
consumers and members of communities in ways that have important moral significance. The impact of innovations can be worldwide from one second to the next, and global dimensions require global responsibility. Companies cannot simply rely upon market forces for dealing with the implications of their developments as if they were as benign as pieces of furniture.

Taking the moral component of innovation seriously is thus a necessity for innovators, arising inevitably from the nature of their work. This calls for an explicit evaluation of the (moral) aims of the innovation and this itself can only be successful if it is underpinned by a sound ethical reflection. Hence, our research calls for a more reflective management approach in such innovation companies. Even though RRI activities are likely to have costs, the familiar utilitarian perspective should reassure companies that this is a good investment for sustainability in the long-term. In addition, following RRI principles can also form part of established activities; for example, they can be used to integrate customers and users into research and development activities. Tools like participatory design or Delphi studies might be applied in such a context (see Martinuzzi et al., 2018).

Companies need to understand that they are part of a social ecosystem, and the sustainability of that ecosystem requires them not only to innovate but to also engage in reflection about their own ethical underpinnings and their (moral) goals. It is vital that these goals are reflected in practice and that they are shared goals through development of an ethical culture. This is likely to be easier for large firms who have the ability and the capacity to dedicate resources to this. But it is also important for start-ups, particularly in technological fields where so many developments come from young, fast-moving operators, to develop an awareness of ethical issues, even though they typically face resource constraints. It is even more incumbent upon larger organisations that take over such small operators to be sure that the moral and ethical concerns are well-considered.

Researchers and innovators are not likely to be moral philosophers, nor do they have to be. We are not arguing for an ethical review of each activity or business goal, but for a general and consistent reflection of the longer-term goals that a company's work is intended to achieve as well as a reasoned explanation of 'why' these goals in particular. In modern pluralistic societies, it would be unreasonable to expect that there is universal agreement on these goals, but it is imperative that companies understand that they are not something separate from society but are part of it. Their comprehension of this social placing could be vital to the longevity of their organisation.

An important starting point for organisations is to clearly state their (moral) aims and objectives. This signals to the outside world of customers, regulators and the greater environment what the organisation is trying to achieve. It has an equally important role in highlighting its standpoint to employees. This is important for assurance of alignment of activities but can also serves to reinforce 
employees' commitment to the organisation and its goals. This type of values-alignment, when the values of organisational personnel are aligned with the values and goals of their organisation, can have an enormous impact upon the success of a company (Henderson, 2003). An organisational set of aims and objectives is often already present in the form of vision or mission statements (for example Google's famed mission statement "Don't be evil"). From an ethical perspective, it is important that this goes beyond being a mere statement and actually has some impact upon the shape of the organisational culture. Establishing an ethically-aware culture is a long-term, thorough-going project that requires top level support and dedication of significant resources to allow organisational members to contribute and be taken seriously.

Many of these considerations are well established in CSR. Our research has shown that they are particularly relevant to research \& development, which is often not explicitly considered in CSR discourses. The concept and principles of RRI can serve to build a bridge between the organisations CSR and sustainability goals and their R\&D activities. What our work has shown is that it is worth not just to think about how CSR and sustainability aims can be integrated into R\&D but that this requires explicit consideration of why an organisation would do so. The integration of explicit normative considerations into R\&D is needed to ensure that the resulting activities are consistent with the broader normative position of the organisation.

\subsection{FURTHER RESEARCH}

This study provides interesting insights, but it could be extended. In particular only EU companies were included and the EU already has a vibrant academic community in RRI-related research as well as robust frameworks for regulation and compliance. Including companies from emerging markets in Asia, or from technology companies from Silicon Valley, might provide different insights on this topic. This is important since new forms of innovation like Frugal Innovation are spreading all over the world (Agarwal and Brem, 2017), and more and more European companies have innovation hubs in Silicon Valley (Berger and Brem, 2017). Furthermore, the focus on ICT firms leads to particular concerns such as data security and other related issues that have recently become more prominent in public discourse. Other sectors, like fast-moving consumer goods, could be examined to discover whether similar considerations apply. In addition, this research reflects a single point in time. Many of the insights related to moral and ethical aspects are subject to change over time and longitudinal studies may detect such changes. Finally, the research approach was qualitative in its nature. This provided in-depth insights, but from a relatively small number of perspectives. Consequently, we cannot draw valid generalisations concerning the entire ICT industry, much less the research and 
innovation activities of other sectors. To gain generalisable insights, a different (and perhaps mixed methods) approach would need to be employed.

\subsection{ConCLUSION}

While there are a number of directions in which this research could be taken further, we hope to have shed light on the types of moral goals that ICT companies set for themselves.

We conclude that deeper recognition of the underlying ethical and moral aspects of innovation are vital for social and environmental sustainability and, ultimately, the sustainability of companies themselves. The ethical considerations that underlie seemingly-objective business decisions such as 'following good practice' need to be better understood in order to continue to improve overall positions of corporate social responsibility. CSR is itself a recognition that private companies form part of the fabric of society but deeper ethical understanding could better inform company policy and company ethos. A failure to do so could lead to public backlash against ICT innovation comparable to that experienced by genetically modified organisms or nuclear technology innovators. This type of backlash could create such a hostile environment for innovation that it would jeopardise the progress of innovation. It is also important for innovators to understand that, as citizens of this world, it is in their interests to improve the quality of life of their fellow citizens. Moral concerns and their ethical underpinnings are crucial for this. Taking them seriously will help ensure that corporate research and development contributes to making this world a better place in the future, rather than simply maximising profits for the few in the short term. 


\section{REFERENCES}

Adam, B., Groves, C., 2011. Futures Tended: Care and Future-Oriented Responsibility. Bull. Sci. Technol. Soc. 31, 17-27. https://doi.org/10.1177/0270467610391237

Agarwal, N., \& Brem, A. (2017). Frugal innovation-past, present, and future. IEEE Engineering Management Review, 45(3), 37-41.

Anichini, G., Cheveigné, S. de, 2012. Overview of research related to science in society in Europe. Sci. Public Policy 39, 701-709. https://doi.org/10.1093/scipol/scs088

Antwi, S.K., Hamza, K.T., 2015. Qualitative and Quantitative Research Paradigms in Business Research: A Philosophical Reflection. European Journal of Business and Management, 7:3, 217-225.

Aristotle, 2007. The Nicomachean Ethics. Filiquarian Publishing, LLC, Minneapolis.

Bailey, M., Burstein, A., Klaffy, K., Clayman, S., Dittrich, D., Heidemann, J., Kenneally, E., Maughan, D., McNeill, J., Neumann, P., Scheper, C., Tien, L., Papadopoulos, C., Visscher, W., Westby, J., 2011. The Menlo Report: Ethical Principles Guiding Information and Communication Technology Research. https://www.caida.org/publications/papers/2012/menlo report actual formatted/ (accessed 30-07-2019).

Barbour, R., 2018. Doing Focus Groups. SAGE, London.

Beauchamp, T.L., Childress, J.F., 2009. Principles of Biomedical Ethics, 6th ed. Oxford University Press, USA.

Berger, A., \& Brem, A. (2017). Why Do European Companies Have Innovation Hubs in Silicon Valley Best Practice Examples and Key Takeaways. Thunderbird International Business Review, 59(6), 757-763.

Berkowitz, H., 2018. Meta-organizing firms' capabilities for sustainable innovation: A conceptual framework. J. Clean. Prod. 175, 420-430. https://doi.org/10.1016/j.jclepro.2017.12.028

Big Innovation Centre, 2017. What is Al? A theme report based on the 1st meeting of the All-Party Parliamentary Group on Artificial Intelligence [APPG Al], London.

Boden, M., Johnston, R., Scapolo, F., 2012. The role of FTA in responding to grand challenges: A new approach for STI policy? Sci. Public Policy 39, 135-139.

Boll, C., Lagemann, A., 2019. The Gender Pay Gap in EU Countries - New Evidence Based on EU-SES 2014 Data. Intereconomics 54, 101-105. https://doi.org/10.1007/s10272-019-0802-7

Boons, F., Montalvo, C., Quist, J., Wagner, M., 2013. Sustainable innovation, business models and economic performance: an overview. J. Clean. Prod., Sustainable Innovation and Business Models 45, 1-8. https://doi.org/10.1016/j.jclepro.2012.08.013

Borenstein, J., 2012. Robotics, ethics, and the environment. Int. J. Technoethics 3, 17-29. https://doi.org/10.4018/jte.2012040103

Bostrom, N., Sandberg, A., 2009. Cognitive enhancement: Methods, ethics, regulatory challenges. Sci. Eng. Ethics 15, 311-341.

Braun, V., Clarke, V., 2006. Using thematic analysis in psychology. Qual. Res. Psychol. 3, 77-101.

Brooks, J., McCluskey, S., Turley, E., King, N., 2015. The utility of template analysis in qualitative psychology research. Qual. Res. Psychol. 12, 202-222.

Brundtland, G.H., 1987. Our Common Future. https://www.are.admin.ch/are/en/home/nachhaltigeentwicklung/internationale-zusammenarbeit/agenda-2030-fuer-nachhaltigeentwicklung/uno-_-meilensteine-zur-nachhaltigen-entwicklung/1987--brundtlandbericht.html (accessed 6.16.19).

Cagnin, C., Amanatidou, E., Keenan, M., 2012. Orienting European innovation systems towards grand challenges and the roles that FTA can play. Sci. Public Policy 39, 140-152.

Carroll, A.B., 1991. The pyramid of corporate social responsibility: Toward the moral management of organizational stakeholders. Bus. Horiz. 34, 39-48. 
Cath, C.J.N., Wachter, S., Mittelstadt, B., Taddeo, M., Floridi, L., 2016. Artificial Intelligence and the "Good Society": The US, EU, and UK Approach (SSRN Scholarly Paper No. ID 2906249). Social Science Research Network, Rochester, NY.

Chatfield, K., latridis, K., Stahl, B.C., Paspallis, N., 2017. Innovating Responsibly in ICT for Ageing: Drivers, Obstacles and Implementation. Sustainability 9, 971. https://doi.org/10.3390/su9060971

Chiappetta Jabbour, C.J., Sarkis, J., Lopes de Sousa Jabbour, A.B., Scott Renwick, D.W., Singh, S.K., Grebinevych, O., Kruglianskas, I., Filho, M.G., 2019. Who is in charge? A review and a research agenda on the 'human side' of the circular economy. J. Clean. Prod. 222, 793-801. https://doi.org/10.1016/j.jclepro.2019.03.038

De George, R. T., 1999. Business Ethics (5th edition). Prentice Hall College Div., New Jersey.

de los Reyes, G., Scholz, M., 2019. The limits of the business case for sustainability: Don't count on 'Creating Shared Value' to extinguish corporate destruction. J. Clean. Prod. 221, 785-794. https://doi.org/10.1016/j.jclepro.2019.02.187

Denscombe, M., 2014. The Good Research Guide: For Small-scale Social Research Projects. McGrawHill Education (UK).

Dreyfus, H.L., 1992. What Computers Still Can't Do: A Critique of Artificial Reason, Revised edition. ed. MIT Press, Cambridge, Mass.

Dyllick, T., Hockerts, K., 2002. Beyond the business case for corporate sustainability. Bus. Strategy Environ. 11, 130-141. https://doi.org/10.1002/bse.323

Eriksson, P., Kovalainen, A., 2015. Qualitative Methods in Business Research: A Practical Guide to Social Research. SAGE, London.

European Commission, 2008. Integrating Ethics in EU Research.

European Commission, 2012. Responsible Research and Innovation - Europe's ability to respond to societal challenges. European Commission, Publications Office, Brussels. https://ec.europa.eu/research/swafs/pdf/pub rri/KI0214595ENC.pdf (accessed 30-07-2019)

European Commission, 2014. Responsible research \& innovation. https://ec.europa.eu/programmes/horizon2020/en/h2020-section/responsible-researchinnovation (accessed 5.11.19).

European Parliament, 2017. Civil Law Rules on Robotics - European Parliament resolution of 16 February 2017 with recommendations to the Commission on Civil Law Rules on Robotics (2015/2103(INL)). http://www.europarl.europa.eu/doceo/document/TA-8-20170051 EN.html (accessed 30-07-2019)

Executive Office of the President, 2016a. Preparing for the Future of Artificial Intelligence. Executive Office of the President National Science and Technology Council Committee on Technology. https://obamawhitehouse.archives.gov/sites/default/files/whitehouse files/microsites/ostp /NSTC/preparing for the future of ai.pdf (accessed 30-07-2019)

Executive Office of the President, 2016b. Artificial Intelligence, Automation, and the Economy. Executive Office of the President National Science and Technology Council Committee on Technology. https://obamawhitehouse.archives.gov/blog/2016/12/20/artificial-intelligenceautomation-and-economy (accessed 30-07-2019)

Fodor, M., Brem, A., 2015. Do Privacy Concerns Matter for Millennials? Results from an Empirical Analysis of Location-Based Services Adoption in Germany. Comput Hum Behav 53, 344-353. https://doi.org/10.1016/j.chb.2015.06.048

Fuchs, C., 2017. Social Media: A Critical Introduction, 2 edition. ed. SAGE Publications Ltd, Thousand Oaks, CA.

Gransche, B., 2016. Ethics of Big Data: Introduction. Int. Rev. Inf. Ethics.

Gurzawska, A., Mäkinen, M., Brey, P., 2017. Implementation of Responsible Research and Innovation (RRI) Practices in Industry: Providing the Right Incentives. Sustainability 9, 1759. https://doi.org/10.3390/su9101759 
Hankins, J., 2012. A Handbook for Responsible Innovation, 1st ed. Fondazione Giannino Bassetti, Milan.

Henderson, M., 2003. Values at Work: The Invisible Threads Between People, Performance and Profit. Harper Collins Publishers, New York, USA.

House of Commons Science and Technology Committee, 2016. Robotics and artificial intelligence. https://publications.parliament.uk/pa/cm201617/cmselect/cmsctech/145/14502.htm (accessed 30-07-2019)

Kant, I., 1797. Grundlegung zur Metaphysik der Sitten. Reclam, Ditzingen.

Kant, I., 1788. Kritik der praktischen Vernunft. Reclam, Ditzingen.

Khushf, G., 2004. Systems theory and the ethics of human enhancement - A framework for NBIC convergence, in: Roco, M.C., Montemagno, C.D. (Eds.), Coevolution of Human Potential and Converging Technologies. New York Academy of Sciences, New York. pp. 124-149.

King, N., 2012. Doing template analysis, in: Symon, G., Cassell, C. (Eds.), Qualitative Organizational Research: Core Methods and Current Challenges. SAGE, London. pp. 426-450.

Landeweerd, L., Townend, D., Mesman, J., Van Hoyweghen, I., 2015. Reflections on different governance styles in regulating science: a contribution to 'Responsible Research and Innovation.' Life Sci. Soc. Policy 11. https://doi.org/10.1186/s40504-015-0026-y

Leisinger, K.M., 2007. Capitalism with a human face: the UN Global Compact. J. Corp. Citizsh. 28, 113-132.

Leisinger, K.M., Chatfield, K., 2019. Working Together to Make the World a Healthier Place: Desiderata for the Pharmaceutical Industry. Cambridge Quarterly of Healthcare Ethics, 28:1, 153-164. https://doi.org/10.1017/S096318011800049X

Levidow, L., Neubauer, C., 2012. Opening Up Societal Futures through EU Research and Innovation Agendas. EASST Rev. 31, 4-11.

Lin, P. a, Abney, K. b c, Bekey, G. a, 2011. Robot ethics: Mapping the issues for a mechanized world. Artif. Intell. 175, 942-949. https://doi.org/10.1016/j.artint.2010.11.026.

Martinuzzi, A., Blok, V., Brem, A., Stahl, B., Schönherr, N., 2018. Responsible Research and Innovation in Industry-Challenges, Insights and Perspectives. Sustainability 10, 702. https://doi.org/10.3390/su10030702

Metcalf, J., Keller, E.F., boyd, danah, 2016. Perspectives on Big Data, Ethics, and Society. Council for Big Data, Ethics, and Society. https://bdes.datasociety.net/wpcontent/uploads/2016/05/Perspectives-on-Big-Data.pdf (accessed 30-07-2019).

Mill, J.S., 1861. Utilitarianism, 2nd Revised edition. ed. Hackett Publishing Co, Inc., Cambridge.

Mittelstadt, B., Floridi, L., 2016. The Ethics of Big Data: Current and Foreseeable Issues in Biomedical Contexts. Sci. Eng. Ethics 22, 303-341. https://doi.org/DOI 10.1007/s11948-015-9652-2

Murray, F., Stern, S., Campbell, G., MacCormack, A., 2012. Grand Innovation Prizes: A theoretical, normative, and empirical evaluation. Res. Policy 41, 1779-1792.

https://doi.org/10.1016/j.respol.2012.06.013

Nuffield Council on Bioethics, 2013. Novel neurotechnologies: intervening in the brain: short guide. http://nuffieldbioethics.org/wpcontent/uploads/2013/06/Novel neurotechnologies report PDF web 0.pdf (accessed 3007-2019).

Oliveira de Paula, G., Negrão Cavalcanti, R., 2000. Ethics: essence for sustainability. J. Clean. Prod. 8, 109-117. https://doi.org/10.1016/S0959-6526(99)00321-2

Opie, C., 2004. Doing Educational Research. SAGE, London.

Orlikowski, W.J., Baroudi, J.J., 1991. Studying Information Technology in Organizations: Research Approaches and Assumptions. Inf. Syst. Res. 2, 1-28.

Owen, R., 2014. The UK Engineering and Physical Sciences Research Council's Commitment to a Framework for Responsible Innovation. J. Responsible Innov. 1, 113-117. https://doi.org/10.1080/23299460.2014.882065 
Pandza, K., Ellwood, P., 2013. Strategic and ethical foundations for responsible innovation. Res. Policy 42, 1112-1125. https://doi.org/10.1016/j.respol.2013.02.007

Richardson, K., 2017. The human relationship in the ethics of robotics: a call to Martin Buber's I and Thou. Al Soc. 1-8. https://doi.org/10.1007/s00146-017-0699-2

Richardson, K., 2016. Sex Robot Matters: Slavery, the Prostituted, and the Rights of Machines. IEEE Technol. Soc. Mag. 35, 46-53. https://doi.org/10.1109/MTS.2016.2554421

Rome Declaration, 2014. Rome Declaration on Responsible Research and Innovation in Europe. https://ec.europa.eu/research/swafs/pdf/rome declaration RRI final 21 November.pdf (accessed 30-07-2019)

Ruggie, J., 2010. Business and Human Rights: Further Steps toward the Operationalization of the "Protect, Respect and Remedy" Framework (Report of the Special Representative of the Secretary-General on the Issue of Human Rights and Transnational Corporations and Other Business Enterprises, UN Doc A/HRC/11/13). United Nations. https://www.businesshumanrights.org/sites/default/files/reports-and-materials/Ruggie-report-7-Apr-2008.pdf (accessed 30-07-2019)

Schomberg, R. von, 2012. Prospects for technology assessment in a framework of responsible research and innovation, in: Dusseldorp, M., Beecroft, R. (Eds.), Technikfolgen abschätzen lehren. Springer VS, Weisbaden. pp. 39-61.

Schwandt, T.A., 2014. The SAGE Dictionary of Qualitative Inquiry. SAGE Publications, London. Smith, A., 1776. An inquiry into the nature and causes the wealth of nations. Penguin, London.

Stahl, B.C., Timmermans, J., Mittelstadt, B.D., 2016. The Ethics of Computing: A Survey of the Computing-Oriented Literature. ACM Comput Surv 48, 55:1-55:38. https://doi.org/10.1145/2871196

Stilgoe, J., Owen, R., Macnaghten, P., 2013. Developing a framework for responsible innovation. Res. Policy 42, 1568-1580. https://doi.org/10.1016/j.respol.2013.05.008

Technopolis, Fraunhofer ISI, 2012. Interim evaluation \& assessment of future options for Science in Society Actions Assessment of future options. technopolis group, Brighton, UK.

The Millennium Project, 2017. State of the Future version 19.0. URL http://www.millenniumproject.org/state-of-the-future-version-19-0/ (accessed 5.07.19).

Thorne, S., 2016. Interpretive Description. Routledge. https://doi.org/10.4324/9781315426259

Timmermans, J., Yaghmaei, E., Stahl, B.C., Brem, A., 2017. Research and innovation processes revisited - networked responsibility in industry. Sustain. Account. Manag. Policy J. 8, 307334. https://doi.org/10.1108/SAMPJ-04-2015-0023

UK Synthetic Biology Roadmap Coordination Group, 2012. A synthetic biology roadmap for the UK. Technology Strategy Board.

https://webarchive.nationalarchives.gov.uk/20130302042701/http://www.innovateuk.org/ assets/tsb syntheticbiologyroadmap.pdf (accessed 30-07-2019).

US Government Printing Office, 2003. 21st Century Nanotechnology Research and Development Act. https://legcounsel.house.gov/Comps/21st\%20Century\%20Nanotechnology\%20Research\%20 And\%20Development\%20Act.pdf (accessed 30-07-2019).

van Est, R., Stemerding, D., Rerimassie, V., Rerimassie, M., Timmer, J., Brom, F., 2014. From bio to NBIC - From medical practice to daily life (Report written for the Council of Europe, Committee on Bioethics). Rathenau Instituut, The Hague. https://pure.tue.nl/ws/portalfiles/portal/117573709/From Bio to NBIC convergence Rath enau.pdf (accessed 30-07-2019).

WBCSD (World Business Council for Sustainable Development), n.d. Our members. https://www.wbcsd.org/Overview/Our-members (accessed 6.16.19).

Weizenbaum, J., 1977. Computer Power and Human Reason: From Judgement to Calculation, New edition. ed. W.H.Freeman \& Co Ltd., New York.

Whetten, D.A., 1989. What Constitutes a Theoretical Contribution? Acad. Manage. Rev. 14, 490-495. Wiener, N., 1954. The human use of human beings. Doubleday, New York. 
Winfield, A., 2019. Alan Winfield's Web Log: An Updated Round Up of Ethical Principles of Robotics and Al. Alan Winfields Web Log. https://alanwinfield.blogspot.com/2019/04/an-updatedround-up-of-ethical.html (accessed 5.17.19).

Winter, S.J., Butler, B.S., 2011. Creating bigger problems: grand challenges as boundary objects and the legitimacy of the information systems field. J. Inf. Technol. 26, 99-108.

Yong, J.Y., Yusliza, M.-Y., Ramayah, T., Chiappetta Jabbour, C.J., Sehnem, S., Mani, V., 2019.

Pathways towards sustainability in manufacturing organizations: Empirical evidence on the role of green human resource management. Bus. Strategy Environ. 1.

https://doi.org/10.1002/bse.2359

Zhang, J.Y., Marris, C., Rose, N., 2011. The Transnational Governance of Synthetic Biology - Scientific uncertainty, cross-borderness and the 'art' of governance (No. 4), BIOS working paper. London School of Economics and Political Science, London. 


\section{APPENDIX A}

\section{Experience and opinions of ICT industry thought leaders on the concept of RRI Interview schedule}

Welcome and thanks for taking the time.

It is important for us to gain perspectives from those actually working in industry. Therefore, real-life experience and practical suggestions are very welcome.

I have some questions but our conversation does not have to be limited to those and please feel free to say if there are certain things that you prefer not to discuss.

Before we begin any questions?

\subsection{INDICATIVE QUESTIONS:}

\subsubsection{Overall experience of RRI}

The purpose of this interview is to seek your opinions about RRI in industry. Is that a concept you have ever come across before?

(Probe further here if necessary and help by offering suggestions to find out about particular ways of how RRI can be recognized in practice)

In your opinion are the types of issues raised by RRI valued in your company? In what ways?

\subsubsection{RRI specifics}

In what ways is consideration paid to your target or end users in research and innovation activities?

(e.g. who is consulted in the development phase, who benefits from it and why these groups, do you interact with NGOs?)

Do you have any particular protocols in place to consider ethical aspects of research and innovation? Any professional ethical codes? (If none then any idea why not?)

What attention is paid to CSR tools such as ISO14001, UN Global Compact, Global Reporting Initiative (GRI), ISO26000, The Ceres Roadmap for sustainability, or other certifications in your company? 
If yes, do you use in-house systems or externally certify/verify these tools

To what extent does your company attempt to predict and assess risks of your product development and later product use, in particular when it comes to impact on the environment, society and the well-being of users?

(Ask about any methods used in this assessment, for example product traceability or any criteria that are used in selection of product/companies further down the supply chain)

Have you or would you consider making the results of your research and/or other innovation data openly available?

(What would be the benefits or reasons why not?)

\subsubsection{Drivers}

In your experience what are the main motivations for this type of activity? (who is in charge, are there any requirements for, and what are people's motivations)

What do you think are the benefits of RRI?

\subsubsection{Deterrents}

In your experience what are the main challenges for development and implementation of RRI?

\subsubsection{Facilitation of RRI}

What do you think would need to be in place to help with those challenges?

Moving forward what do you think can be done to encourage and facilitate RRI?

\subsubsection{Anything else}

Anything else you would like to add? 


\section{APPENDIX B}

\section{Responsible Industry Focus Group Questions}

Please note that these are indicative questions. There is flexibility to discuss other issues that you think are relevant.

1. Have you heard of Responsible Research and Innovation before? If yes, in which context?

2. Please tell us what you would consider responsible practice in R\&D and how your organisation ensures that it acts responsibly.

3. Are you aware of irresponsible practices in your industry? Can you give examples?

4. In your opinion, what are reasons why people don't act responsibly? What could be done to encourage responsible practice in $R \& D$ ?

\section{Key responsibilities for $R R I$ within the organization}

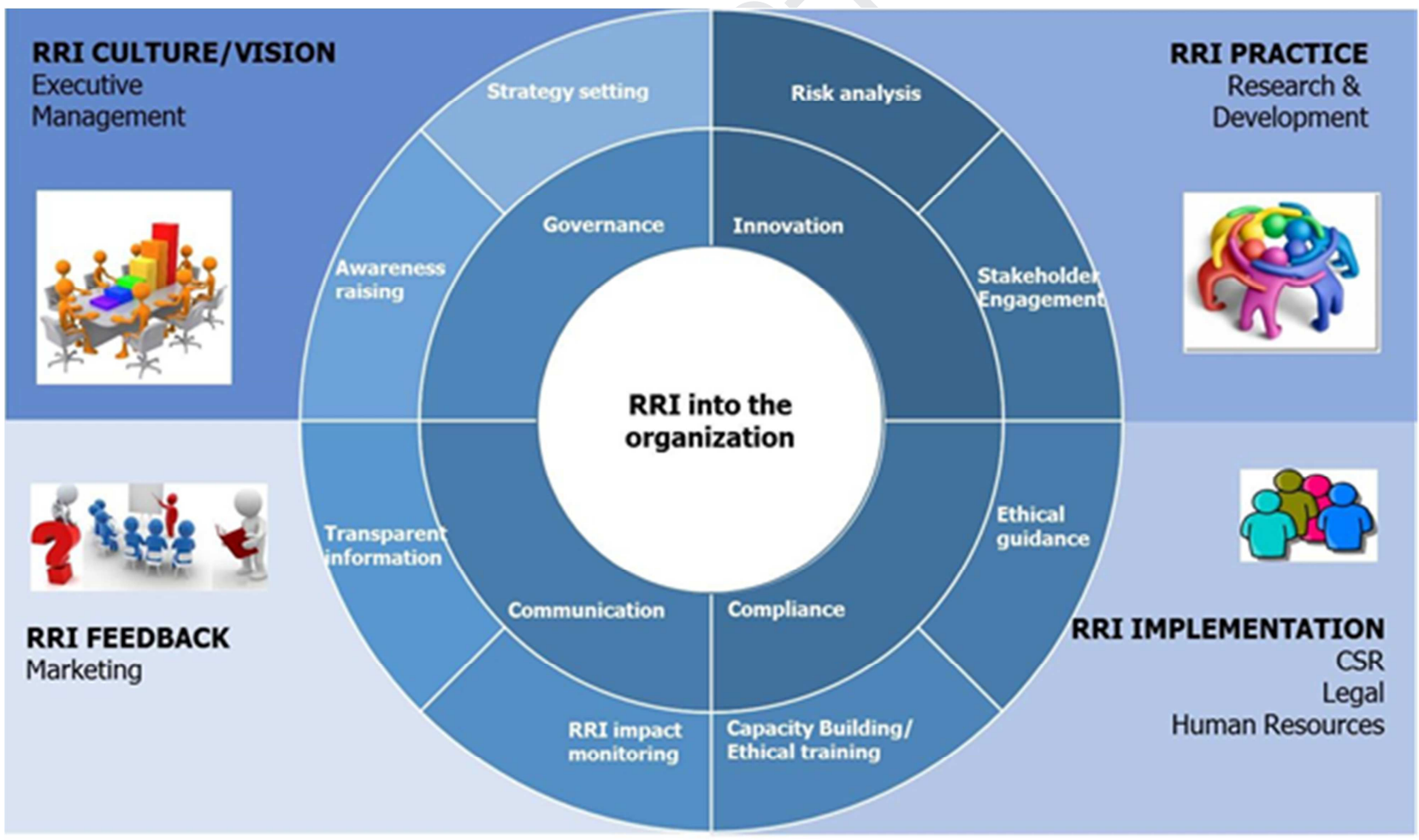

Does your organisation cover all of these aspects? Which ones do you think are more important than others? 


\section{Journal Pre-proof}

\section{Scheme of activities to be undertaken for the integration of RRI along the whole value chain}

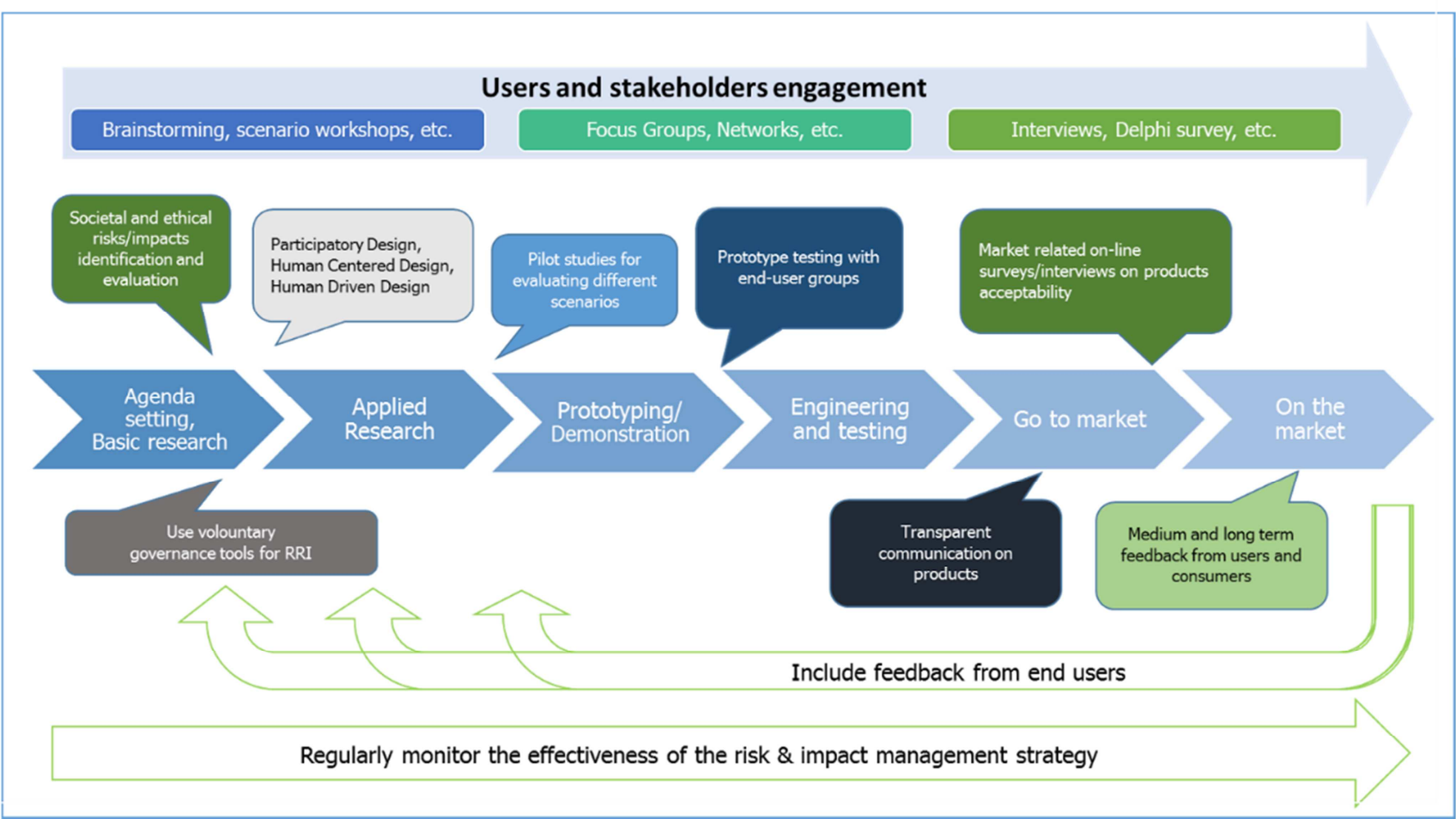

Which ones of the activities depicted here are relevant to your company? Why? Do you think further ones would be desirable?

7. Stakeholders involvement in the different phases of risk/impact assessment.

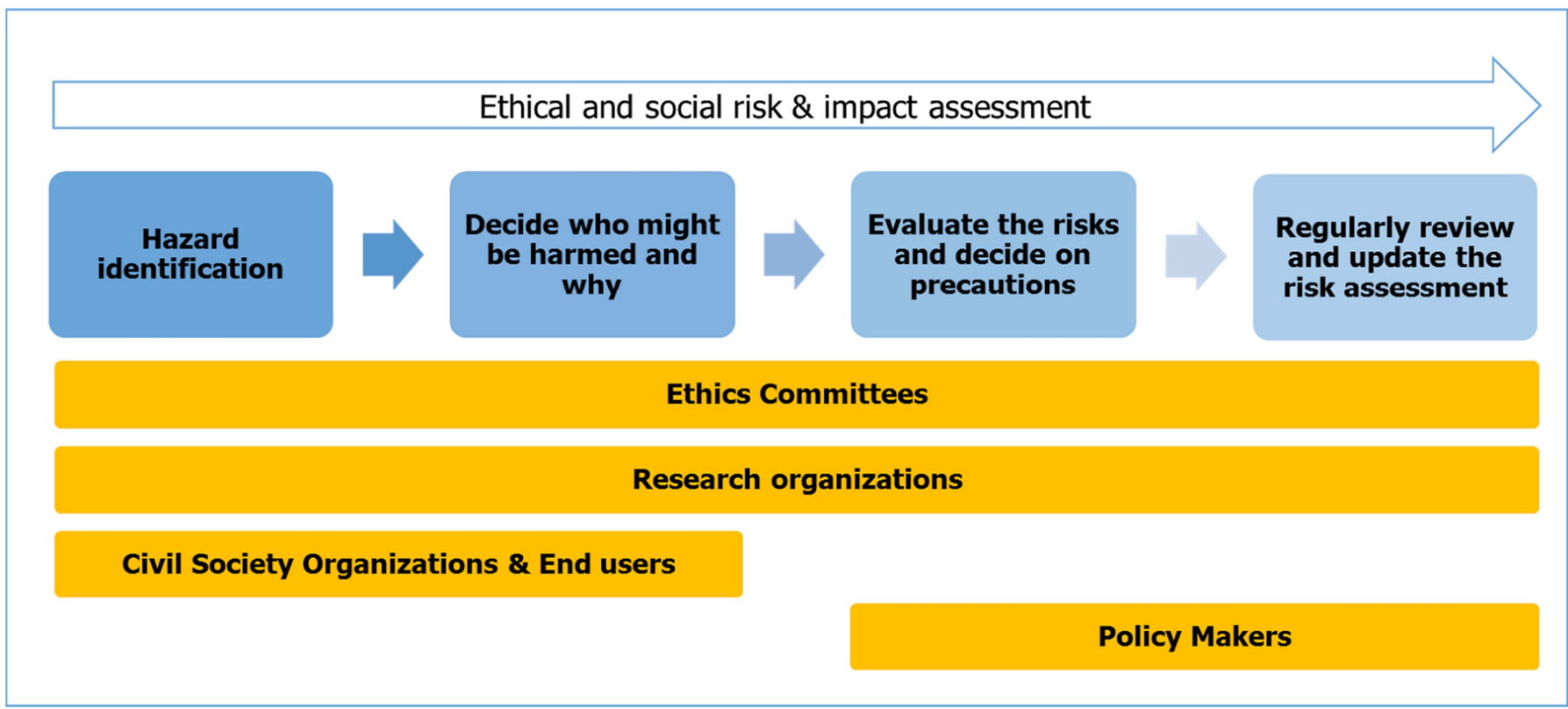

Which stakeholders does your company engage with? How does this happen? Are you aware of any problems? 
8. We have shared one of the outcomes of our work with you, which we have called "implementation plan". For your everyday work, what parts of the document do you find relevant? Why?

- Which parts do you find difficult to carry out? And why?

- What reasons do you see for using such a plan?

- What could be additional benefits for your company or your products/services?

- What could the IP improve in your work and/or that of your colleagues?

9. What topics or aspects of the IP or in general RRI do you find unrealistic for industry?

10. Open Access is an important part of RRI but might be difficult to realize in the industry sector. Do you agree?

11. Where do you conflict between the demands of RRI and the goals of industry?

12. For the IP to actually work, it should be presented and distributed in a way that appeals to the users in industry. The goal is to come up with a form that is practical and useful in everyday work flows.

- What format do you find appealing?

- For example: IP as a website, document, or program?

- Who do you think would be a good target group within you company? (e.g. CEOs, researchers, management level, administration)

- How do you think we can reach these target groups best?

- What do they need from such a plan?

13. Would your organisation be likely to adopt such a framework?

14. How should the framework be developed to be relevant to your organisation (e.g. standard, legislation, industry initiative)?

15. How could RRI be integrated into your company / the ICT industry as a whole?

16. Are there any aspects we haven't discussed yet and that you would like to add? 


\section{Ethics in Corporate Research \& Development}

\section{What is it?}

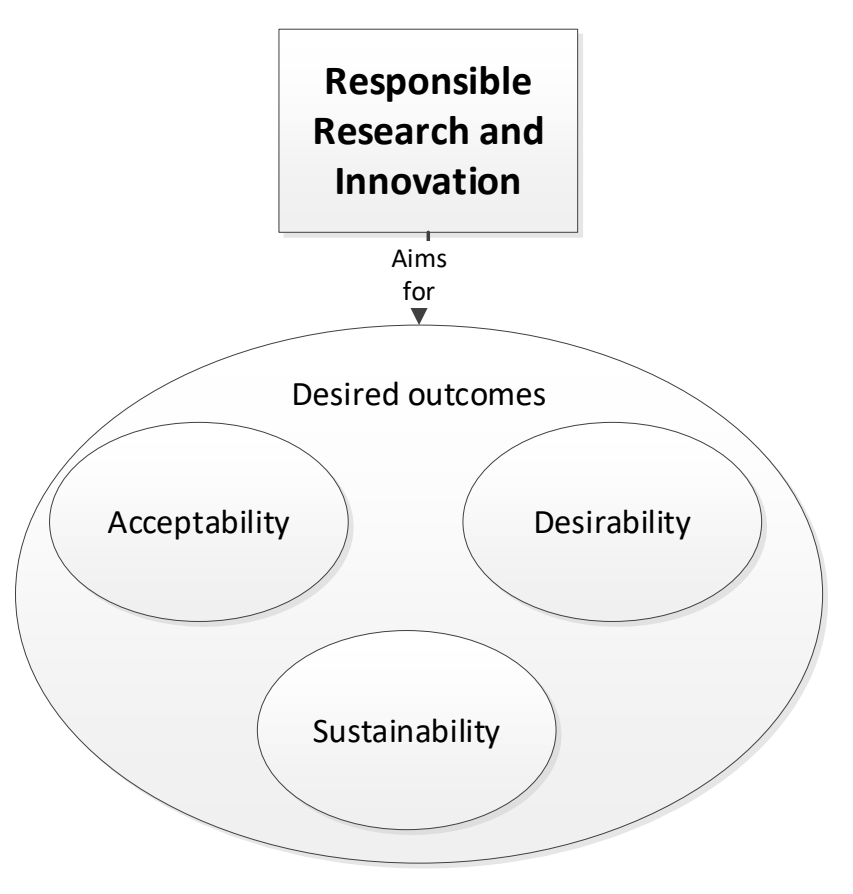

Why do it? (Literature)

Why do it? (Findings)
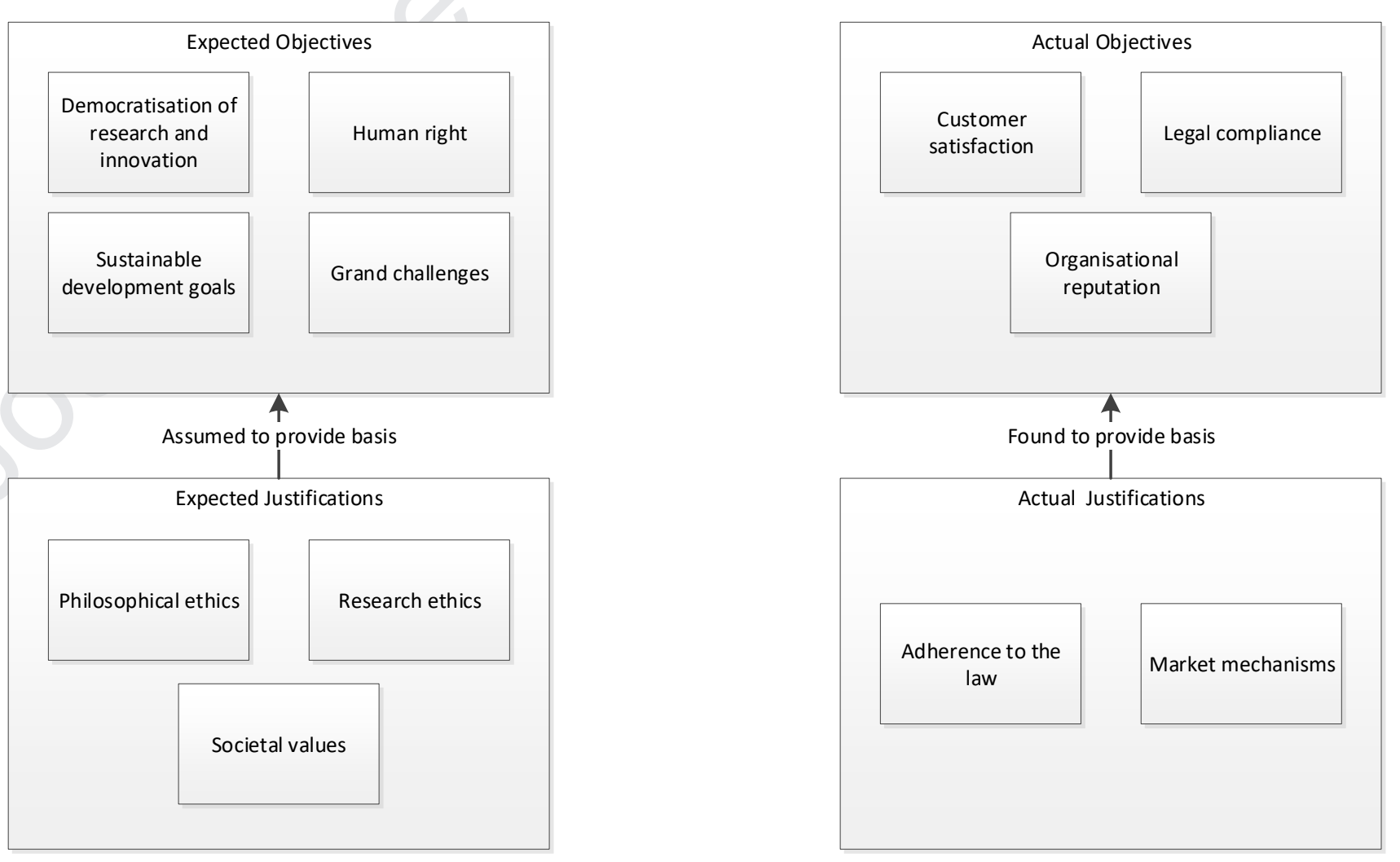


\section{Highlights}

- Private companies engage, to a limited extent, with responsible research and innovation (RRI)

- ICT companies demonstrate no aspirations to contribute towards grand societal challenges

- Companies cannot rely upon market forces for dealing with the implications of their research and development (R\&D) activities

- Reflection upon the ethical underpinnings of research and innovation are vital for sustainability

- Companies should clearly articulate and enact their moral aims and objectives 